\title{
Droplet Ignition in a High-Temperature Convective Environment
}

\author{
LUNG-WEEI HUANG AND CHIUN-HSUN CHEN* \\ Department of Mechanical Engineering, National Chiao Tung University, Hsinchu, Taiwan 30050 , \\ Republic of China
}

\begin{abstract}
The behaviors of $n$-heptane droplet ignition in a high-temperature convective environment are studied numerically. Two cases are considered wherein one is a purely forced convection, and the other is a mixed convection. The ignition process can be divided into a heating-up evaporation, a nearly constant droplettemperature evaporation and a constant droplet-temperature burning. During the heating-up evaporation stage, the droplet temperature rises sharply and the square of the diameter decreases slightly with time. In the next stage, the droplet remains at nearly constant temperature in a pure vaporization process. After ignition, an envelope flame appears and the droplet is in an augmented vaporization process. The $d^{2}$-law still holds. In the mixed convection case, where the gravity effect is taken into consideration, the location of initiation of chemical reaction is closer to the droplet, the ignition takes place earlier, and the flame is subjected to more stretch. The fuel accumulation phenomenon is also identified and it results in a suppression of the fuel evaporation rate. Finally, several future extensions are proposed to further modify the combustion model. (C) 1997 by The Combustion Institute
\end{abstract}

\section{NOMENCLATURE}

$\bar{B} \quad$ frequency factor for gas-phase reaction

$\bar{C}_{p} \quad$ average specific heat

$\bar{D}$ dimensional species diffusivity

Da Damköhler number

$\bar{E} \quad$ activation energy for gas-phase reaction

$f \quad$ stoichiometric oxidizer/fuel mass ratio

$\bar{k} \quad$ thermal conductivity

Le Lewis number, $\bar{\alpha} / \bar{D}$

$\bar{M} \quad$ average molecular weight

$\overline{\dot{m}}_{w}$ fuel evaporation rate

$\bar{p} \quad$ pressure

Pr Prandtl number, $\bar{C}_{p} \bar{\mu} / \bar{k}$

$\bar{Q}$ heat of combustion per unit mass of fuel

$\bar{L} \quad$ latent heat of fuel

$R^{o} \quad$ universal gas constant

$\bar{d}$ droplet diameter

Re Reynolds number

$\bar{T} \quad$ temperature

$\bar{u}_{\infty} \quad$ incoming oxidizer velocity

$\bar{u} \quad$ velocity in $z$-direction

$\bar{l} \quad$ velocity in $r$-direction

$\bar{z} \quad$ distance along $z$-direction

$\bar{r} \quad$ distance along $r$-direction

$Y_{f} \quad$ mass fraction of fuel, $\rho_{f} / \rho$

$Y_{v}$ mass fraction of oxidizer, $\left(\rho_{f} / \rho\right) / Y_{0 \infty}$

\author{
$\bar{\mu} \quad$ dynamic viscosity \\ $\bar{\rho}$ density \\ $\dot{\omega}$ nondimensional reaction rate
}

\section{Superseripts}

* reference state dimensional quantities

\author{
Subscripts \\ $f \quad$ fuel \\ $o$ oxidizer \\ $w$ surface of the droplet surface \\ $s g$ property at initial droplet temperature \\ $\infty \quad$ ambient \\ $n, t$ normal and tangential to droplet surface
}

\section{INTRODUCTION}

The present work is concerned with the ignition behaviors of a droplet subjected to a high-temperature convective environment. To date, the detailed behavior of gas-phase ignition in a convective flow field has not been well understood by analytic or experimental observation. Because there are some difficulties with experimental observation of droplet ignition in a convective environment, a simulation model becomes an important tool when attacking such a problem. When a droplet is suddenly placed

\footnotetext{
* Corresponding author.
} 
in a hot convective environment, the droplet gets heated and its temperature rises. The gasification fuel vapor from the droplet surface causes the droplet diameter to gradually decrease. In addition, the vapor mixes with air. Once the equivalent ratio of the fuel-air mixture is within the ignition domain, it begins to react. This chemical reaction further influences the flow and thermal fields in the gas phase and, eventually, the heat transfer rate along the fuel surface, and ignition takes place. Apparently, the processes are coupled together, making the problem extremely complex. In order to describe the ignition process, complete conservation equations of continuity, energy, and species, as well as the NavierStokes' momentum equations, are needed for solution.

In the early work of Nishiwaki [1], the concept of ignition delay was pointed out. The time of ignition delay can be separated into two parts: the time required to raise the droplet temperature up to the beginning of evaporation and the time between the start of evaporation and ignition. El-Wakil and Abdou [2] also reported that the ignition of a droplet may be considered as consisting of two stages: a preheat stage and an ignition beginning stage. During the first stage, the droplet is heated without significant evaporation and it is insensitive to composition and temperature. The second stage, involving gas-phase ignition, is extremely dependent on molecular composition of the fuel and on temperature. The total ignition delay time, including the physical and chemical delay times, were also estimated in their study. The total ignition time is the sum of the evaporation time and the reaction time for ignition.

There have been many studies attempting to compute the ignition delay time, such as those by Faeth and Olson [3], Sangiovanni and Kesten [4], Saitoh and Nagano [5], and Rah et al. [6]. These works suffered inaccurate representation due to the indefinite nature of the criteria by which the ignition delay time is estimated, as described by Rah et al. [6]. In addition, these models were too complex and not suitable for use in spray. Law [7] derived an ignition criterion by using a matched-asymptotic analysis in the limit of large activation energy. The gas phase was assumed quasi-steady and burned in a zero-gravity environment. The ignition criterion derived by Law is widely used in spray. However, Law's criterion requires that the reaction order does not deviate much from one and has no convective flow at all, thus limiting its application. In a subsequent work of Mawid and Aggarwal [8], they extended Law's analysis to examine the effect of the reaction order with respect to both fuel and oxidizer on the ignition criterion. A new critical Damköhler number was obtained.

Generally, droplet ignition eventually is in a convective environment. Takei et al. [9] experimentally investigated the ignition of a suspended fuel droplet in an atmospheric environment. They found that for pure hexadecane droplet ignition, delay time increases with an increase of initial droplet diameter. On the other hand, the delay time decreases for pure heptane droplet ignition, especially under a lower temperature environment. Volatility plays an important role in ignition delay time. An experimental work by Wong and Ho [10] investigated the convective ignition process of suspended fuel droplets. The incoming flow velocity was varied from $u_{x}=0.8$ to $2.8 \mathrm{~m} / \mathrm{s}$ and the gas temperature was varied from $\bar{T}_{x}=$ 900 to $1600 \mathrm{~K}$. The fuel used was $n$-heptane, $n$-dodecane, and $n$-hexadecane. They found that the ignition process was initiated far downstream from the droplet, when $\bar{T}_{x}$ was below $1300 \mathrm{~K}$. For example, the beginning location of the premixed flame was at a distance of 25 to $40 d_{0}$ for $\bar{T}_{x}<1000 \mathrm{~K}$. However, its value was 3 to $10 d_{0}$ for $\bar{T}_{x}=1150$ to $1300 \mathrm{~K}$. As the ambient temperature was increased to $1500 \mathrm{~K}$, the ignition occurred directly around the droplet. The beginning position of premixed flame was not significantly different for the three different fuels. This indicated that the volatility of fuel has little influence on the beginning position of premixed flame. The ignition delay time was found to be insensitive to flow velocity $(\mathrm{Re}<17)$ when the ambient temperature was $1073 \mathrm{~K}$ and the initial droplet diameter was $1550 \mu \mathrm{m}$. As the Reynolds number increased to 21 , the ignition delay times increased considerably. As the Reynolds num- 
ber was further increased, no ignition occurred. The experimental results showed that forced convection was disadvantageous for droplet ignition.

The theoretical work by Rangel and Fernandez-Pello [11] studied droplet ignition in mixed convection by using a boundary layer approximation. The effect of local Damköhler on forward ignition mechanism was investigated. Their model was limited to a high Reynolds number and Grashof number because of the boundary layer approximation, and it is completely invalid beyond the separation point. Dash and Som [12] investigated the ignition and combustion of liquid droplets in a forced convection. They used quasi-steady momentum equations for both the gas and liquid phases and an unsteady source term was added to the conservation equations for energy and species. They found that there exists a minimum droplet diameter at a given ambient temperature, below which burning is difficult. This minimum droplet diameter decreases with a decreasing initial Reynolds number. Also, a minimum ignition delay time exists with an increasing initial Reynolds number. This indicated that forced convection under certain physical situations will be advantageous to the ignition, and decrease the ignition delay time. However, the ignition position was not discussed in their work. Yang and Tsai [13] numerically studied the convective ignition and flame development over a porous sphere. The full set of conservation equations in two dimensions with finiterate global kinetics was adopted to simulate the physical and chemical processes during the evaporation and burning of a porous sphere. The effects of Damköhler and Lewis numbers on the ignition delay time, and the period of flame development, were clearly demonstrated. An ignition criterion chosen by the zero temporal gradient of the heat flux to droplet surface was used in their study. The position of ignition was near the forward stagnation point for a small Lewis number or a large Damköhler number. However, for a large Lewis number or a small Damköhler number, ignition was initiated in the wake region. The heat-up process was not considered as the temperature of the porous sphere was assumed to be a constant.
In addition, the size of the porous sphere in their study remains a constant. Apparently, it is difficult to accurately describe the ignition process of a real droplet subjected to a hot convective environment.

From this literature review, we can see that, so far, only the works of Rangel and Fernandez-Pello [11] investigated the behaviors of droplet ignition in a mixed convective environment. However, ignition involves a very dramatic variation in the gas phase. In addition, Wong and Ho's experiments also showed that the ignition is initiated far downstream from the droplet and the premixed flame moves upstream. After ignition, an envelope flame appears and surrounds the droplet. It is clear that the degenerated boundary layer approximation is not sufficient to describe these features. When complete conservation equations were considered, either the droplet itself was treated as having a constant temperature and constant diameter porous sphere, or the gravity in the gas phase was neglected in advance. Therefore, we attempted to set up a model to simulate and study the behaviors of droplet ignition in a convective environment and, subsequently, to understand the controlling mechanism involved. In addition, the droplet was subjected to both a forced convective and a mixed convective environment. Thus, we will have a better understanding of the effect of gravity on droplet ignition.

\section{MATHEMATICAL MODEL}

In order to make this complicated problem more tractable, the following assumptions are made in the mathematical formulation of the combustion model.

1. It is restricted to a spherical droplet without internal circulation. In other words, the droplet is approximated as a porous rigid sphere. The droplet temperature is spatially uniform, but varies temporally.

2. The fluid is of the Newtonian type, and the flow is axis-symmetrical and laminar. Radiant heat transfer is negligible.

3. The ideal gas law is applied to the gas mixture with constant and equal specific 
heat, equal diffusion coefficients, and constant Prandtl and Lewis numbers. A relationship between the mixture viscosity and temperature is also assumed.

4. The viscous dissipation and compressive work are neglected due to the low-speed combustion problem.

In this study, the fuel is $n$-heptane and its combustion process is described by a one-step overall chemical reaction. The fuel vapor reacts with oxidizer to form products and release heat simultaneously, or

$1 \mathrm{~kg}[$ fuel $]+f \mathrm{~kg}$ [oxidizer]

$$
\rightarrow(1+f) \mathrm{kg}[\text { product }]+Q \mathrm{~kJ}[\text { heat }],
$$

where $f$ and $Q$ represent the stoichiometric oxidizer/fuel mass ratio and the heat of combustion per unit mass of fuel, respectively. The relationship between the mass and energy source terms is

$\overline{\dot{\omega}}_{f}=\overline{\dot{\omega}}_{o} / f=-\overline{\dot{Q}} / \bar{Q}$.

The corresponding chemical kinetics for the burning of $n$-heptane is adopted from Westbrook and Dryer [14]. After mathematical manipulation, it is expressed as

$$
\overline{\dot{\omega}}_{f}=\bar{B} \bar{Y}_{o \infty}{ }^{3 / 2} \rho^{1.75} Y_{f}^{1 / 4} Y_{o}^{3 / 2} \exp \left(-\bar{E} / R^{o} \bar{T}\right),
$$

where $Y_{o}=\bar{Y}_{o} / \bar{Y}_{o \infty}$ and $\bar{B}$ and $\bar{E}$ are the frequency factor and the activation energy, respectively.

Before the actual computation, a nondimensionalization procedure is performed. The nondimensional variables and parameters are specified in advance:

$$
\begin{aligned}
& z=\frac{\bar{z}}{\bar{d}}, \quad r=\frac{\bar{r}}{\bar{d}}, \quad u=\frac{\bar{u}}{\bar{u}_{\infty}}, \quad v=\frac{\bar{v}}{\bar{u}_{\infty}}, \\
& p=\frac{\bar{P}-\bar{P}_{r c}}{\bar{\rho}_{\infty} \bar{u}_{\infty}^{2}}, \quad T=\frac{\bar{T}}{\bar{T}_{\infty}}, \\
& \rho=\frac{\bar{\rho}}{\bar{\rho}_{\infty}}, \quad \mu=\frac{\bar{\mu}}{\bar{\mu}_{\infty}}, \\
& \operatorname{Re}=\frac{\bar{\rho}_{\infty} \bar{u}_{\infty} \bar{d}}{\bar{\mu}_{\infty}}, \quad \operatorname{Pr}=\frac{\bar{\mu} \bar{C}_{p}}{\bar{k}},
\end{aligned}
$$

$\mathrm{Le}=\frac{\bar{k}}{\bar{\rho}_{\infty} \bar{C}_{p} \bar{D}}, \quad G=\frac{\bar{G}}{\bar{\rho}_{\infty} \bar{u}_{\infty}}$

$Q=\frac{\bar{Q}}{\bar{C}_{p} \bar{T}_{\infty}}, \quad E=\frac{\bar{E}}{R^{o} \bar{T}_{\infty}}$,

$\mathrm{Da}=\frac{\bar{d} \bar{B}}{\bar{\rho}_{\infty} \bar{u}_{\infty}}, \quad \mathrm{Gr}=\frac{\bar{g}\left(\bar{\rho}_{s g}-\bar{\rho}_{\infty}\right) \bar{d}^{3}}{\bar{\rho}_{\infty} \bar{\nu}_{\infty}^{2}}$,

$t=\frac{\bar{t}}{\bar{d}_{0} / 4 \bar{\alpha}_{1}}, \quad \operatorname{Pr}_{1}=\frac{\bar{v}_{1}}{\bar{\alpha}_{1}}$,

where the overbar represents the dimensional quantities. Note that we adopt the instantaneous droplet diameter, $\bar{d}$, as the reference length. The advantage of doing so is that the normalized droplet diameter is maintained as unity at any time. Therefore, the computational domain does not need to be adjusted with the change of the droplet diameter (or time, implicitly), and the subtle variations can be captured even if the real diameter becomes very small. However, $\bar{d}$ is contained in three dimensionless parameters, the Damköhler number ( $\mathrm{Da}$ ), the Grashof number (Gr), and the Reynolds number (Re). They need to be updated for each time interval, which increases the computational complexity to some extent.

Based on these nondimensional variables and parameters, the dimensionless governing equations and boundary conditions are presented as follows.

\section{Governing equations}

Continuity equation:

$\frac{\partial \rho}{\partial t} \frac{4}{\operatorname{Re} \operatorname{Pr}_{1}} \frac{v_{1}}{d_{0}^{2}}+\frac{\partial(\rho u)}{\partial z}+\frac{1}{r} \frac{\partial(\rho v r)}{\partial r}=0 ;$

$z$-Momentum equation:

$$
\begin{aligned}
\frac{\partial \rho u}{\partial t} \frac{4}{\operatorname{Re} \operatorname{Pr}_{1}} \frac{v_{1}}{d_{0}{ }^{2}}+\rho u \frac{\partial u}{\partial z}+\rho v \frac{\partial u}{\partial r} \\
=-\frac{\partial p}{\partial z}+\frac{\partial}{\partial z}\left\{\frac { \mu } { \operatorname { R e } } \left[2 \frac{\partial u}{\partial z}-\frac{2}{3}\right.\right. \\
\left.\left.\quad \times\left(\frac{1}{r} \frac{\partial}{\partial r}(r v)+\frac{\partial u}{\partial z}\right)\right]\right\} \\
+\frac{1}{r} \frac{\partial}{\partial r}\left[\frac{\mu}{\operatorname{Re}} r\left(\frac{\partial u}{\partial r}+\frac{\partial v}{\partial z}\right)\right]
\end{aligned}
$$




$$
+\frac{\mathrm{Gr}}{\operatorname{Re}^{2}} \frac{1-\rho}{\rho_{s g}-1}
$$

r-Momentum equation:

$$
\begin{aligned}
\frac{\partial \rho u}{\partial t} \frac{4}{\operatorname{Re} \operatorname{Pr}_{1}} \frac{v_{1}}{d_{0}{ }^{2}}+\rho u \frac{\partial v}{\partial z}+\rho v \frac{\partial v}{\partial r} \\
=-\frac{\partial p}{\partial z}+\frac{\partial}{\partial z}\left\{r \frac { \mu } { \operatorname { R e } } \left[2 \frac{\partial v}{\partial z}-\frac{2}{3}\right.\right. \\
\left.\left.\quad \times\left(\frac{1}{r} \frac{\partial}{\partial r}(r v)+\frac{\partial u}{\partial z}\right)\right]\right\} \\
+\frac{\partial}{\partial z}\left[\frac{\mu}{\operatorname{Re}}\left(\frac{\partial u}{\partial r}+\frac{\partial v}{\partial z}\right)\right]+\frac{\mu}{\operatorname{Re}} \frac{1}{r} \\
\quad \times\left\{\frac{2 v}{r}-\frac{2}{3}\left[\frac{1}{r} \frac{\partial}{\partial r}(r v)+\frac{\partial u}{\partial z}\right]\right\}
\end{aligned}
$$

Energy equation:

$$
\begin{gathered}
\frac{\partial \rho T}{\partial t} \frac{4}{\operatorname{Re}_{\operatorname{Pr}_{1}}} \frac{v_{1}}{d_{0}^{2}}+\rho u \frac{\partial T}{\partial z}+\rho v \frac{\partial T}{\partial r} \\
=\frac{1}{\operatorname{Re}^{2} \operatorname{Pr}_{1}}\left[\frac{1}{r} \frac{\partial}{\partial r}\left(r \mu \frac{\partial T}{\partial r}\right)\right. \\
\left.+\frac{\partial}{\partial z}\left(\mu \frac{\partial T}{\partial z}\right)+Q \dot{\omega}_{F}\right]
\end{gathered}
$$

Fuel species equation:

$$
\begin{gathered}
\frac{\partial \rho Y_{f}}{\partial t} \frac{4}{\operatorname{Re} \operatorname{Pr}_{1}} \frac{v_{1}}{d_{0}^{2}}+\rho u \frac{\partial Y_{f}}{\partial z}+\rho v \frac{\partial Y_{f}}{\partial r} \\
=\frac{1}{\operatorname{Re} \operatorname{Pr} \operatorname{Le}}\left[\frac{1}{r} \frac{\partial}{\partial r}\left(r \mu \frac{\partial Y_{f}}{\partial r}\right)\right. \\
\left.+\frac{\partial}{\partial z}\left(\mu \frac{\partial Y_{f}}{\partial z}\right)-\dot{\omega}_{F}\right]
\end{gathered}
$$

where

$$
\dot{\omega}_{f}=\mathrm{Da} \bar{Y}_{o x}^{3 / 2} \rho^{1.75} Y_{f}^{1 / 4} Y_{o}^{3 / 2} \exp (-E / T)
$$

is the nondimensional fuel reaction rate and a corresponding ignition domain, $0.5 \leq \phi \leq 4.5$, is imposed. These are adopted from Westbrook and Drye [14].
Oxidizer species equation:

$$
\begin{aligned}
\frac{\partial \rho Y_{o}}{\partial t} & \frac{4}{\operatorname{Re} \operatorname{Pr}_{1}} \frac{v_{1}}{d_{0}^{2}}+\rho u \frac{\partial Y_{o}}{\partial z}+\rho v \frac{\partial Y_{o}}{\partial r} \\
= & \frac{1}{\operatorname{Re} \operatorname{Pr} \operatorname{Le}}\left[\frac{1}{r} \frac{\partial}{\partial r}\left(r \mu \frac{\partial Y_{o}}{\partial r}\right)\right. \\
& \left.+\frac{\partial}{\partial z}\left(\mu \frac{\partial Y_{o}}{\partial z}\right)-\frac{f}{Y_{o \infty}} \dot{\omega}_{F}\right]
\end{aligned}
$$

Equation of state:

$\rho T=1$,

and the viscosity variation with temperature is taken to be

$\mu=T^{0.7}$.

The dimensionless boundary conditions are: at $z \rightarrow-\infty$ (far upstream),

$\begin{array}{ll}u=1, & v=0, \quad T=1, \\ Y_{f}=0, & Y_{o}=1 .\end{array}$

Note that the ambient oxygen index becomes unity because the mass fraction of oxidizer $\left(\bar{Y}_{o}\right)$ is normalized by its ambient value; see Eq. 3:

at $z \rightarrow+\infty$ (far downstream),

$$
\frac{\partial u}{\partial z}=\frac{\partial v}{\partial z}=\frac{\partial T}{\partial z}=\frac{\partial Y_{f}}{\partial z}=\frac{\partial Y_{o}}{\partial z}=0
$$

These conditions imply that there is no downstream influence on the upstream.

at $r \rightarrow+\infty$,

$u=1, \quad v=0, \quad T=1$,

$Y_{f}=0, \quad Y_{o}=1$.

Along the symmetric lines at $r=0, z<-0.5$, or $z>0.5$ :

$$
\begin{aligned}
& \frac{\partial u}{\partial z}=0, \quad v=0, \\
& \frac{\partial T}{\partial z}=\frac{\partial Y_{f}}{\partial z}=\frac{\partial Y_{o}}{\partial z}=0 .
\end{aligned}
$$


Along the droplet surface, $-0.5 \leq z \leq 0.5$, $\sqrt{z^{2}+r^{2}}=0.5$ :

$V t=0, \quad G_{w}=\rho_{w} v_{n}$,

$G_{w} Y_{o w}=\left.\left(\frac{\mu}{\operatorname{RePr} \operatorname{Le}}\right)_{w} \frac{\partial Y_{o}}{\partial n}\right|_{w}$,

$G_{w} Y_{f w}=G_{w}+\left.\left(\frac{\mu}{\operatorname{RePr} \operatorname{Le}}\right)_{w} \frac{\partial Y_{f}}{\partial n}\right|_{w}$,

$Y_{f w}=1 /\left[1+\frac{M_{a}}{M_{f}}\left(\frac{\bar{P}_{x}}{P_{l}}-1\right)\right]$,

where $\bar{P}_{t}=27.048 \exp (A)$, in which

$$
\begin{aligned}
A= & \frac{1}{1-X}\left[-7.67468 X+1.37068 X^{1.5}\right. \\
& \left.-3.5362 X^{3}-3.20243 X^{6}\right],
\end{aligned}
$$

and

$X=1-\bar{T} / 540.3$,

where $M_{a}$ and $M_{f}$ are the molecular weights of air and fuel, and $\bar{P}_{\infty}$ and $\bar{P}_{t}$, represent the ambient pressure and vapor pressure, respectively, which is a function of surface temperature (Reid et al. [15]).

Finally, the instantaneous energy conservation for the droplet is given by

$$
\left.\frac{\partial T}{\partial n}\right|_{w}=\frac{G_{w}}{\mu_{w}} L \operatorname{Pr} \operatorname{Re}+\frac{2}{3} \frac{1}{\mu_{w}}\left(\frac{k_{1}}{d_{0}^{2}}\right) \frac{d T_{w}}{d t} .
$$

Note that $\operatorname{Re}$ is also a function of time, as mentioned previously.

An $r-z$ body-fitted coordinate system is adopted to generate grids by a grid generation technique (Thomas and Middecoff [16]) because the configuration of the flow field shown in Fig. 1 is irregular. Using this procedure, the physical domain is transformed into a computational domain of equal-spaced and square grids. Then, the governing equations transformed due to the mapping process are solved in the computational domain using the SIMPLEC algorithm developed by Van Doormaal and Raithby [17]. The computational domain can be reduced to the half domain because of the symmetry with respect to the $z$ axis. The
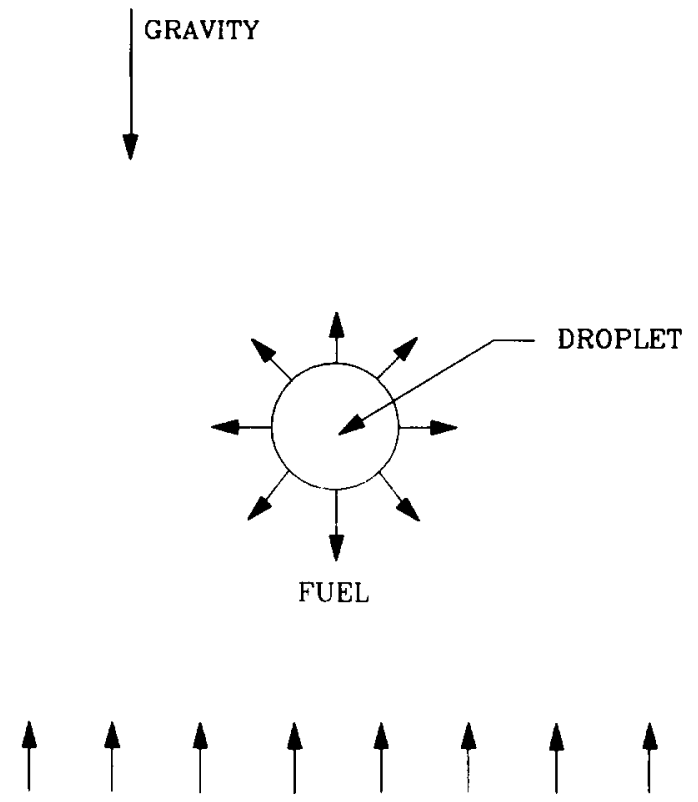

UNIFORM AIR FLOW

Fig. 1. Schematic configuration of a single $n$-heptane droplet ignition in a high-temperature convective environment.

domain of computation is chosen to be $z_{\min }=$ $-22, z_{\max }=30$, and $r_{\max }=30$. The grid distribution is $(115,51)$ and there are 19 grid points along the half-droplet surface in the angular direction. This development procedure is very complicated and tedious, and so we have formulated it into a step-by-step program. The development of this numerical method and executing procedure is described in detail in our earlier papers [18-20]. The control of truncation error for the single time-stepping in the present model is accomplished using an implicit scheme which was described in Ref. [20].

\section{RESULTS AND DISCUSSION}

The fuel properties (Table 1) are adopted from Kanury [21]. The activation energy $E$ in the one-step kinetics still retains the one adopted from Westbrook and Dryer [14]. However, the comparison with experimental measurements of Takei et al. [9] is used to determine the preexponential factor $B$. The normalized parameters are summarized in Table 2.

At $t=0$, a cold $n$-heptane droplet is suddenly placed in a high-temperature convective 
TABLE 1

Property Values

\begin{tabular}{llll}
\hline \multicolumn{1}{c}{ Name } & Symbol & \multicolumn{1}{c}{ Value } & \multicolumn{1}{c}{ Unit } \\
\hline Density (reference) & $\bar{\rho}_{x}$ & 1.1766 & $\mathrm{~kg} / \mathrm{m}^{3}$ \\
Viscosity (reference) & $\bar{\mu}_{\infty}$ & $1.853 \times 10^{-5}$ & $\mathrm{~kg} / \mathrm{ms}$ \\
Velocity (reference) & $\bar{u}_{x}$ & 1.32 & $\mathrm{~m} / \mathrm{s}$ \\
Specific Heat & $\bar{C}_{p}$ & 1.3 & $\mathrm{~kJ} / \mathrm{kg} \mathrm{K}$ \\
Frequency Factor & $\bar{B}$ & $4.966 \times 10^{7}$ & $\mathrm{~kg} / \mathrm{m}^{3} \mathrm{~s}$ \\
Activation Energy & $\bar{E}$ & $1.254 \times 10^{5}$ & $\mathrm{~kJ} / \mathrm{kg}$-mole \\
Heat of Reaction & $\bar{Q}$ & $4.414 \times 10^{4}$ & $\mathrm{~kJ} / \mathrm{kg}$-fuel \\
\hline
\end{tabular}

environment. Two different ambient conditions, termed Case 1 and Case 2, respectively, are imposed around the droplet with an initial diameter of $d_{10}=1.02 \mathrm{~mm}$. In Case 1 , the environment is a purely forced convective flow without considering the gravitational effect, whereas in Case 2, the natural convection is included, which is a mixed convection. The incoming velocity is set at $\bar{u}_{x}=11.4 \mathrm{~cm} / \mathrm{s}$, corresponding to $\mathrm{Re}=1$, and the ambient temperature is $\bar{T}_{x}=973 \mathrm{~K}$. The nondimensional time interval is chosen as 0.01 , corresponding to $0.03115 \mathrm{~s}$ dimensionally. However, a time step, $\Delta t=0.001$, is used when ignition is about to begin. The computation is carried up to $t=0.514 \mathrm{~s}$, when the droplet diameter is around $76 \%$ of its initial value.

TABLE 2

Nondimensional Parameters

\begin{tabular}{|c|c|c|}
\hline Symbol & Definition & Value \\
\hline $\mathrm{Da}$ & $\frac{\overline{d B}}{\bar{\rho}_{\infty} \bar{u}_{x}}$ & Variable \\
\hline $\mathrm{Gr}$ & $\frac{\overline{\mathrm{g}}\left(\bar{\rho}_{s g}-\bar{\rho}_{x}\right) \bar{d}^{3}}{\bar{\rho}_{x} \bar{\nu}_{x}{ }^{2}}$ & Variable \\
\hline $\mathrm{Re}$ & $\frac{\bar{\rho}_{x} \bar{u}_{x} \bar{d}}{\bar{\mu}_{x}}$ & Variable \\
\hline $\mathrm{Pr}$ & $\bar{l} / \bar{\alpha}$ & 0.811 \\
\hline Le & $\bar{\alpha} / \bar{D}$ & 1.0 \\
\hline$Q$ & $\frac{\bar{Q}}{\bar{C}_{p} \bar{T}_{x}}$ & 38.8806 \\
\hline$E$ & $\frac{\bar{E}}{R^{o} \bar{T}_{x}}$ & 15.0966 \\
\hline$L$ & $\frac{\bar{L}}{\bar{C}_{p} \bar{T}_{\infty}}$ & 0.3188 \\
\hline
\end{tabular}

Among the several different definitions for ignition criterion are included the zero temporal gradient of the heat flux to the droplet surface (Yang and Tsai [13]), the first appearance of a temperature-time inflection (Dash and Som [12]), and a sudden jump in droplet temperature or the establishment of an envelope diffusion flame (Rosner [22]). The final one is adopted here to define the occurrence of ignition. The other two ignition criterion are also discussed using the following figure.

Figure 2 presents the temporal variations of the droplet temperature $T_{w}$, the maximum temperature in the flow field $T_{\max }$, and the local surface heat flux $q$ for two locations $\left(\theta=0^{\circ}\right.$ and $180^{\circ}$, respectively) in Case 1 . The droplet combustion behaviors can be divided into three stages accordingly: the heating-up evaporation, followed by a nearly constant droplet-temperature evaporation, and a constant droplet-temperature burning. A sharp change, i.e., ignition, occurs between the final two stages. Rosner [22] observed a similar trend, in which the droplet was suddenly placed in a quiescent environment. According to Rosner's definition, $t=0.25 \mathrm{~s}$ is the end of heating-up evaporation. During this stage, droplet temperature rises rapidly, then reaches a nearly constant value of $335 \mathrm{~K}$. Beyond that, the evaporation proceeds at a constant temperature up to $t=0.386 \mathrm{~s}$. Ignition then takes place. In an extremely short period of roughly $0.003 \mathrm{~s}$, the droplet temperature jumps to 359 $\mathrm{K}$, which is near its wet-bulb temperature of burning. Thereafter, a flame appears and surrounds the droplet. Restated, the combustion of the droplet turns into the constant droplettemperature burning.

Here, for fuel droplets with a lower boiling temperature or $n$-heptane droplets with much smaller initial droplet diameters, considerable evaporation occurs and even ignition (also depending on the gas-phase conditions) occasionally occurs before the droplet reaches its wetbulb temperature.

The results indicate that the local surface heat-flux distributions at forward and rear points decrease monotonically as a function of time during the period of heating-up evaporation. Such a decrease occurs because the droplet is heated and its temperature 


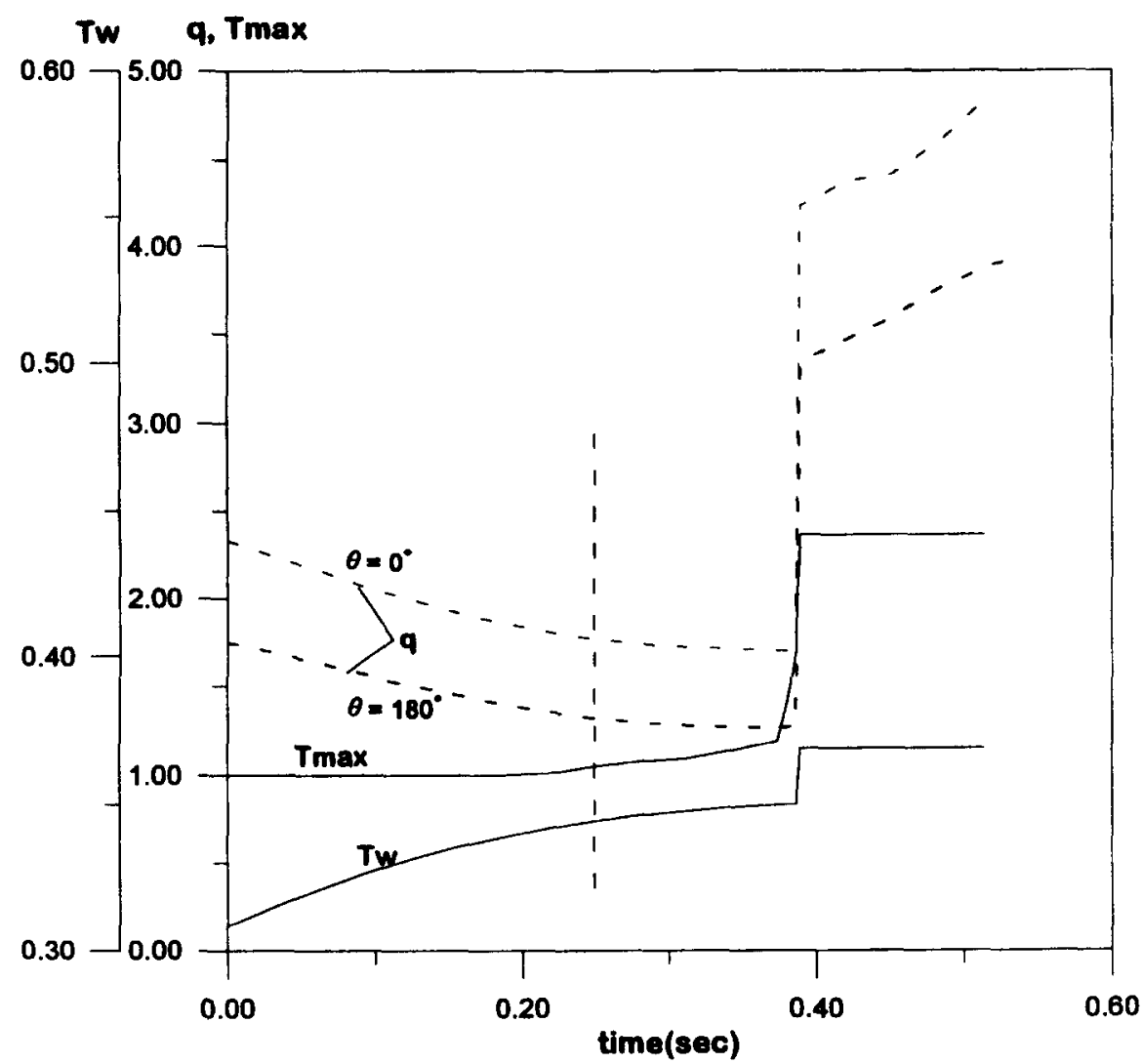

Fig. 2. Droplet temperature $\left(T_{w}\right)$, the maximum temperature $\left(T_{\max }\right)$, and local surface heat flux ( $q$ for $\theta=0^{\circ}$ and $180^{\circ}$ ) versus time for Case 1 .

rises. Meanwhile, the evaporating cold fuel vapor cools down the gas-phase temperature near the droplet. Consequently, the difference between those two temperatures becomes increasingly smaller. Finally, the decrease rates become extremely small in the constant temperature-evaporation period. Moreover, the gas-phase chemical reaction becomes increasingly active with time. Therefore, the maximum temperature also increases. Upon reaching a critical value, the reaction rate accelerates suddenly and substantially. Meanwhile, the maximum temperature rises abruptly to an adiabatic value. At this time, ignition takes place. Therefore, the heat flux to the droplet begins to sharply increase. Interestingly, the criterion of ignition used by Yang and Tsai [13] and Dash and Som [12] is almost the same as that by Rosner [22], which is adopted in this study.
We can conclude that those ignition criteria are roughly identical for $n$-heptane in a hightemperature convective environment.

Figure 3 shows the square of droplet diameter $\bar{d}^{2}$, the mean surface heat flux $Q$, and the mass evaporation rate $\overline{\dot{m}}$ versus time, for Case 1. During the heating-up stage, a small change in droplet diameter indicates that most of the heat from the gas phase is used to raise the droplet temperature, as can be confirmed in Fig. 2.

Because the current model does not consider the mechanism of liquid thermal expansion, results in the initial period cannot directly compare with the experimental ones. This would imply that the square of the droplet diameter at the beginning does not decrease significantly or increase with an increase of time.

After that stage, an approximately linear re- 
lation appears between $\bar{d}^{2}$ and time, indicating that the $d^{2}$-law exists during the constant droplet-temperature evaporation. The evaporation constant is $0.75 \mathrm{~mm}^{2} / \mathrm{s}$. After ignition occurs, a flame surrounds the droplet and the $\bar{d}^{2}$ again appears linear with time. The predicted evaporation constant during the constant droplet-temperature burning is found to be $2.21 \mathrm{~mm}^{2} / \mathrm{s}$, which is greater than that in the former stage.

This value, $2.21 \mathrm{~mm}^{2} / \mathrm{s}$, is also expected greater than the measured one because the current model does not consider the internal flow circulation and the heat transfer inside the droplet, by which part of the heat from the gas phase is consumed.

The mean heat-flux profile over the droplet is quite similar to the local heat-flux distributions shown in Fig. 2. This similarity implies that the heat-flux profiles versus time at each point along the surface are similar. Also, Eq.
18 indicates that part of the heat from the gas phase is used for gasifying the droplet, and the rest raises the droplet temperature. Therefore, the evaporation rate rises sharply at the beginning of heating-up. During the nearly constant droplet-temperature evaporation period, the heating-up gradually ends and the mass evaporation rate slightly increases. After ignition, the evaporation rate starts to decline as time passes because the droplet surface area $\left(\bar{d}^{2}\right)$ is markedly reduced.

The heat transfer mode used here significantly affects the combustion characteristics. Law [23] contended that applying different heat transfer models changes the local heat-flux distributions, thereby affecting the ignition phenomena greatly. As stated above, the assumption of spatially uniform temperature distribution in the droplet is expected to increase the evaporation constant and reduce the ignition time and the downstream ignition distance

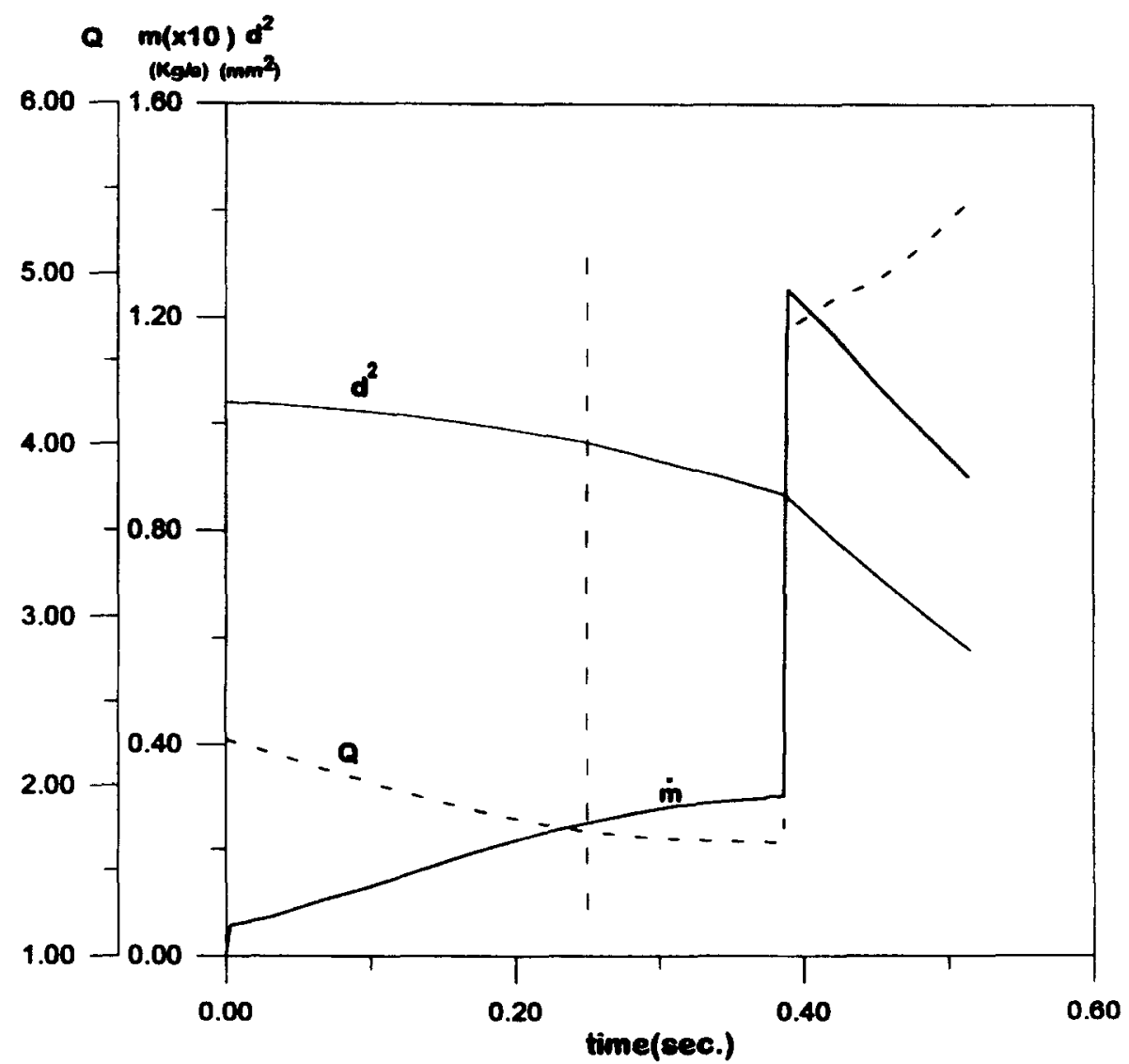

Fig. 3. The square of droplet diameter $\left(\bar{d}^{2}\right)$, the mean surface heat flux $(Q)$, and the mass evaporation $(\dot{m})$ for Case 1 . 
from the droplet. These issues are addressed later.

Figures 4 and 9 display the processes of ignition and flame development for both cases, respectively. The detailed flame structures are described here only for Case 1 using Figs. 4-6 because in general the structures are similar to Case 2. Figure 4 shows a series of changes for the combination of the velocity vector field and isotherm distributions for the droplet in a purely forced convective flow (Case 1), which illustrates the interaction between fluid mechanics and combustion. For comparison, the velocity and length scales at any instant are divided by the relative reference scales at $t=$ $0.343 \mathrm{~s}$. At $t=0.343 \mathrm{~s}$, which is in the constant-droplet-temperature evaporation stage, the fuel vapor has slightly reacted with the air downstream. Because the droplet is cold, the nearby gas-phase temperature is the lowest in the entire flow field. Having an active chemical reaction around the droplet is extremely difficult, even if the local concentration of fuel vapor is high. This reaction can be clearly found in Fig. 4 for the isotherm $\bar{T}=960 \mathrm{~K}$, and in Fig. 5 for the distributions of fuel mass fraction. The fuel vapor is convected downstream by the flow to mix with air and to gain heat. Upon reaching the flammable domain, the fuel-air mixture begins reacting because the ambient temperature is high. Figure 4 reveals that the onset of active chemical reaction occurs at a distance of between six to ten droplet diameters, measured from the center of the droplet. As mentioned in the Introduction, Wong and Ho [10] reported that the beginning position of a premixed flame was at a distance of 25 to 40 times the initial droplet diameter when $\bar{T}_{\infty}$ is below $1100 \mathrm{~K}$. Directly comparing this finding with ours is difficult because of the differences in droplet size and incoming velocity. However, a comparison can be made from the Damköhler number. The Damköhler number, defined in Wong and Ho [10], has the form of

$$
\begin{aligned}
\mathrm{Da}= & A \rho_{\infty}{ }^{1.75} Y_{f}^{0.25} Y_{o}^{1.5} \\
& \times \exp \left(-E_{a} / R_{u} T_{\infty}\right) /\left(U_{\infty} / d_{0}\right) .
\end{aligned}
$$

Substituting the experimental conditions and
$1150 \mathrm{~K}<\bar{T}_{x}<1300 \mathrm{~K}$ into the Damköhler number of this study reveals that it is on the same order of magnitude as that of the experiments. The initial position of a premixed flame in the experimental measurements was three to ten times that of the initial droplet diameter. This finding suggests that this study correlates with the experimental measurements.

Figure 4 indicates that the reacting region gradually grows in size and moves upstream. Meanwhile, the fuel evaporation rate continues to increase because it receives more heat from the environment. Consequently, the reaction zone moves closer to the droplet. As soon as the critical point is reached, such as $t=$ $0.386 \mathrm{~s}$, ignition occurs. Within an extremely short period, the chemical reaction accelerates rapidly and an envelope flame is fully developed, as shown at $t=0.389 \mathrm{~s}$. After ignition, it is the constant droplet-temperature burning, as shown at $t=0.514 \mathrm{~s}$. The flame size decreases with a decrease in the droplet diameter. A detailed explanation of flame structures in the constant droplet-temperature burning stage is not provided here; Huang and Chen [19] offer further details.

Figure 5 shows the distributions of fuel $\left(Y_{f}\right)$ and oxidizer $\left(Y_{o}\right)$ mass fractions with respect to time. This figure reveals that the fuel and oxidizer have been fully premixed before ignition. The air-fuel mixture is convected downstream to gain heat and then react to produce a premixed flame. After ignition, we see that the overlap between the mass fraction distributions of fuel and oxidizer is quite narrow, and it encloses the whole droplet, indicating a pure diffusion flame.

Figure 6 presents the distribution of nondimensional reaction rate of fuel, defined as $\dot{\omega}_{f}=\mathrm{Da} \bar{Y}_{o}^{1.5} \rho^{1.75} Y_{f}^{0.25} Y_{o}^{1.5} \exp (-E / T)$. At $t=$ $0.343 \mathrm{~s}$, the reaction zone is wider but the value is lower because of the slower chemical reaction rate. The location of the maximal chemical rate does not always coincide with that of the highest flame temperature. This is because the rate of reaction depends not only on the temperature, but also on the concentrations of fuel and oxidizer. The reaction zone moves upstream and becomes smaller. However, the value increases with time, indicating that the reaction of fuel and oxidizer becomes 

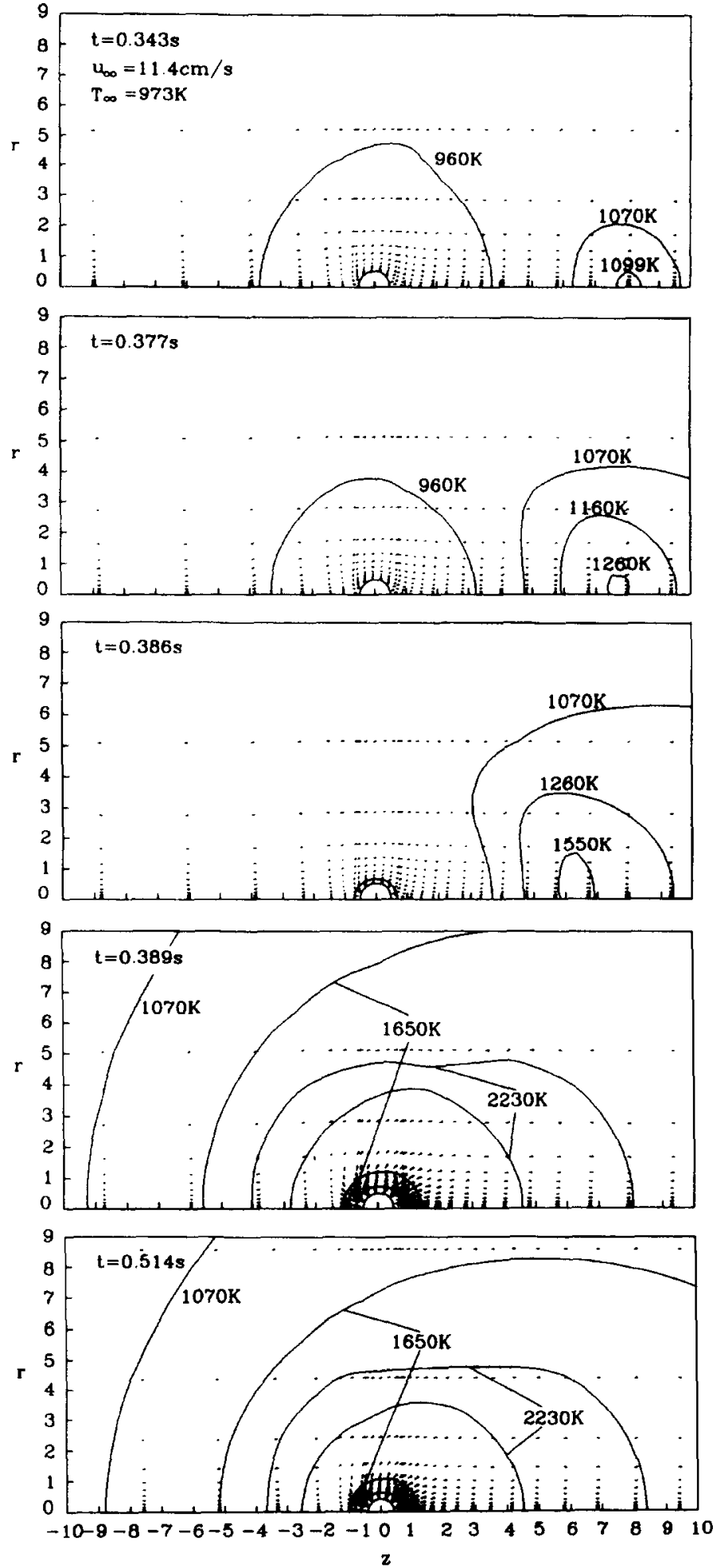

Fig. 4. Isotherm distributions for Case 1. 

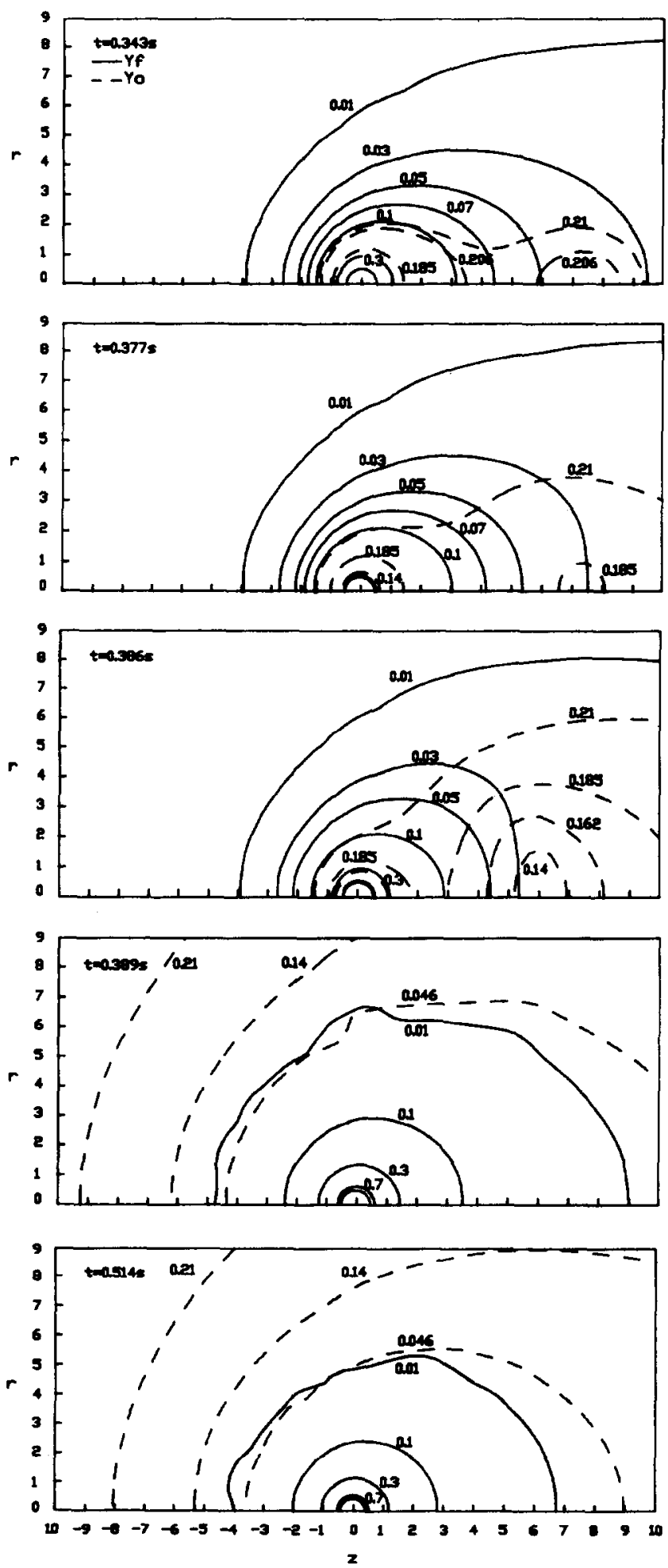

Fig. 5. Fuel and oxidizer mass fraction distributions for Case 1. 

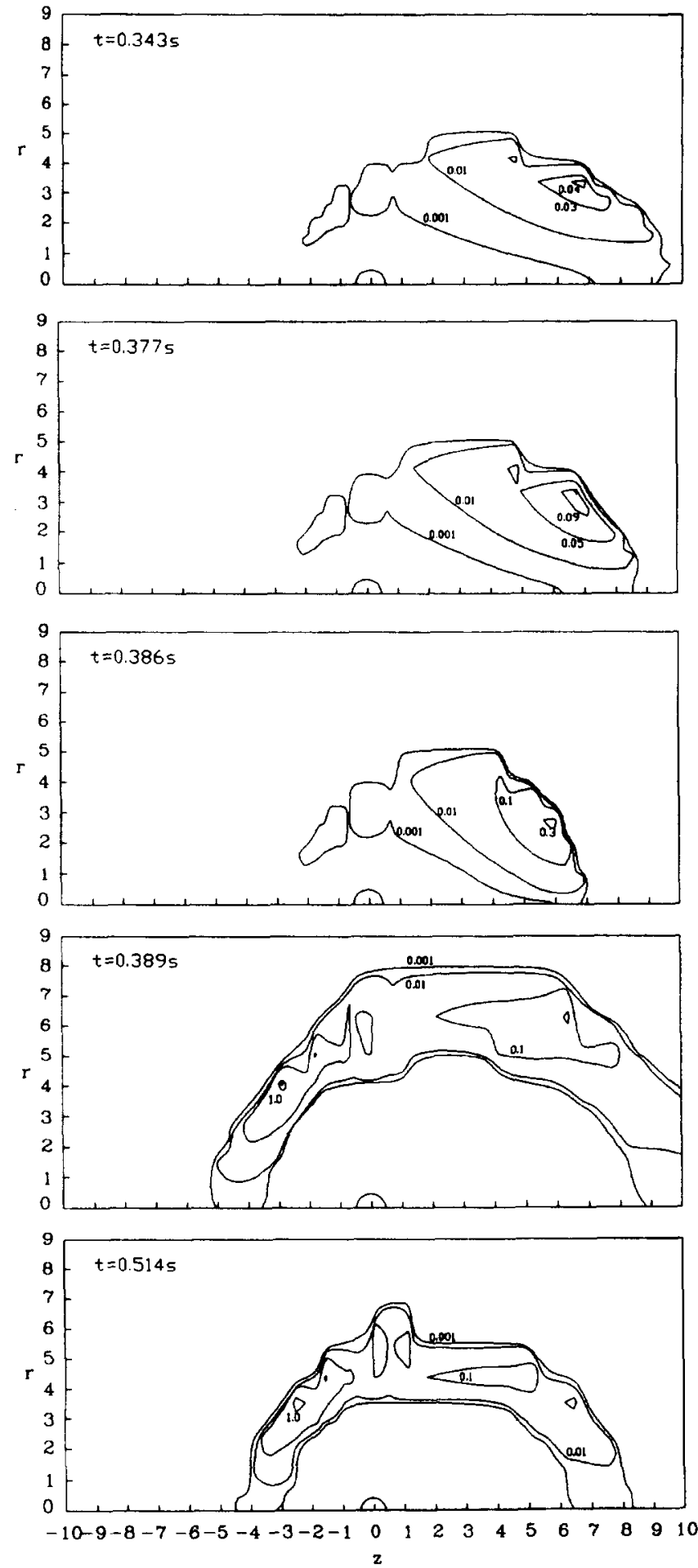

Fig. 6. Nondimensional fuel reaction rate for Case 1. 


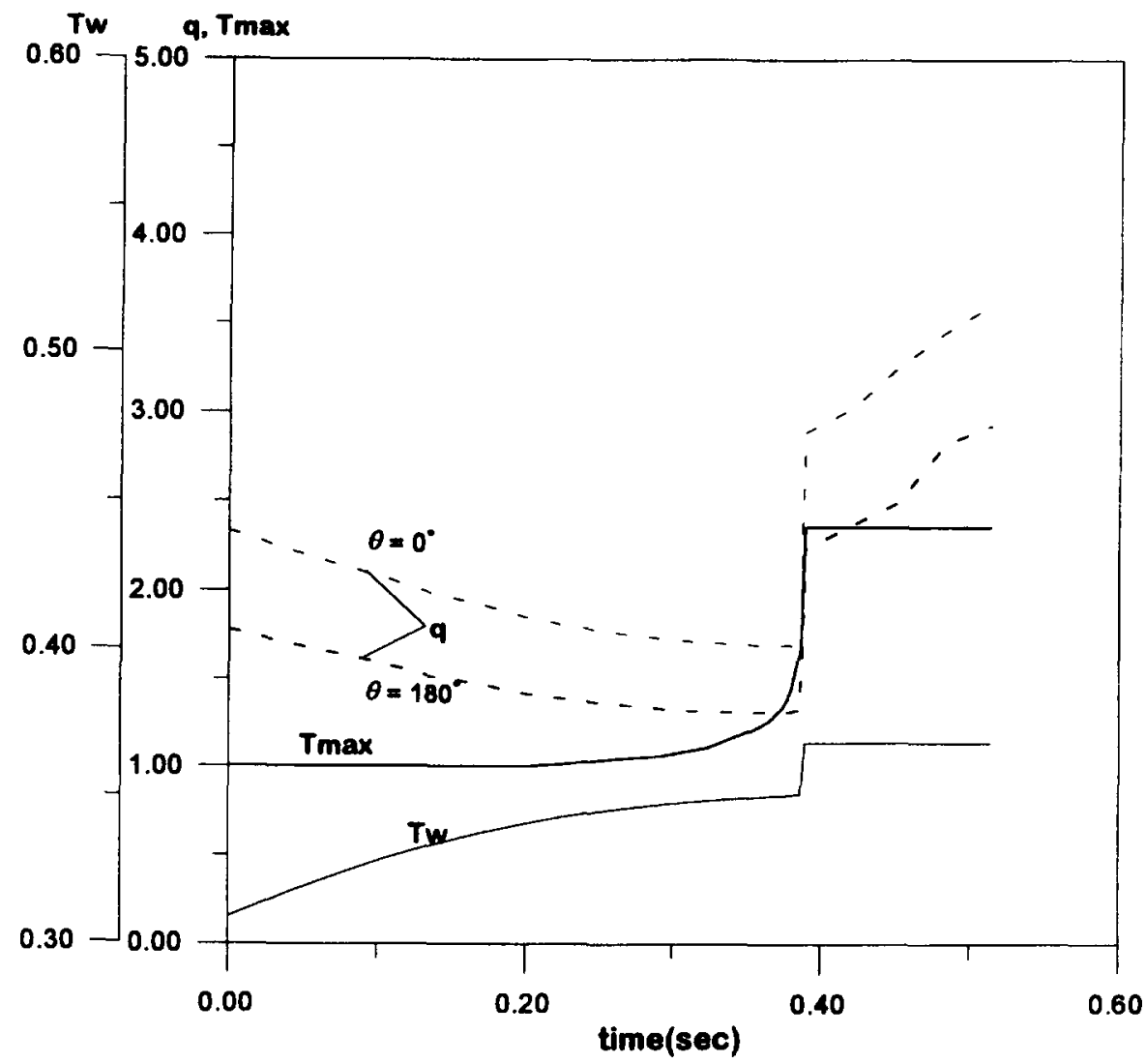

Fig. 7. Droplet temperature $\left(T_{w}\right)$, the maximum temperature $\left(T_{\max }\right)$, and local surface heat flux ( $q$ for $\theta=0^{\circ}$ and $180^{\circ}$ ) versus time for Case 2 .

increasingly dramatic. Once the reaction rate strength is sufficient to overcome the convection strength, the reaction zone completely surrounds the droplet and ignition occurs. Figure 6 indicates that the fuel-air mixture is too rich to react near the droplet.

The effects of the imposed flammability limit in Eq. 9 are discussed in the following. Some numerical experiments were performed. Those results indicated that $T_{\max }$ in the case subjected to the imposed flammability limit was always slightly lower than the one without the limit as time proceeded. Meanwhile, no detectable difference was found in ignition times for both cases. Of course, the primary advantage of the imposition is that it can save much computational time without sacrificing the important features for the problem, as mentioned above.

Figure 7 shows the temporal variations in Case 2 of the droplet temperature $T_{w}$, the maximum temperature in the flow field $T_{\max }$, and the local surface heat flux $q$ for two locations ( $\theta=0^{\circ}$ and $180^{\circ}$, respectively). This figure reveals that the trend is similar to Case 1 (Fig. 2). However, the local surface heat flux in Case 2 is greater than that of Case 1 before ignition, indicating that gravity conduces the fuel to gasify. This occurs because the buoyancy force is in an opposite direction with respect to the incoming flow due to the cold air-fuel mixture. Under this condition, the flow near the droplet is somewhat decelerated and more heat can be conducted into the droplet. After ignition, the local surface heat flux in Case 2 becomes lower. Similar behaviors are also found in Ref. 20, which investigated the transient combustion characteristics of a droplet suddenly exposed to the envelope flame in an atmospheric environment. This is due to fuel accumulation, as clearly illustrated in Fig. 8. 
Figure 8 shows the square of the droplet diameter $\bar{d}^{2}$, the mean surface heat flux $Q$, and the mass evaporation rate $\overline{\dot{m}}$, all versus time, for Case 2. Comparison with Fig. 3 reveals that the mass evaporation rate in Case 2 is greater than that in Case 1 before ignition. In addition, the buoyancy forces somewhat decelerate the flow near the droplet. This finding suggests that more fuel can be accumulated around the droplet. As is well known, the fuel vapor accumulation suppresses the fuel evaporation rate. Therefore, the mean heat flux and mass evaporation rate are smaller in Case 2 after ignition.

Figure 9 is similar to Fig. 4 except that it is a mixed convection environment, assigned as Case 2. This figure indicates that the initiation of the chemical reaction is located at a distance of about five to eight droplet diameters downstream of the droplet, which is shorter than Case 1. This is because, at the beginning, the buoyancy force is in the opposite direction with respect to the incoming flow. Under this condition, most of the fuel remains around the droplet, and the rest is convected downstream. Although the ambient temperature is high far downstream, there is only a slight amount of fuel vapor in the region. Initiating the chemical reaction is a difficult task. The region close to the droplet has much fuel vapor, but the ambient temperature is low. More time is required to start the reaction. Consequently, the initiation of the chemical reaction is closer to the droplet. In this study, the times for the onset of chemical reaction, defined as the time when the maximum temperature starts to be greater than ambient, is $0.218 \mathrm{~s}$ for Case 1 and $0.23 \mathrm{~s}$ for Case 2 . Once the chemical reaction

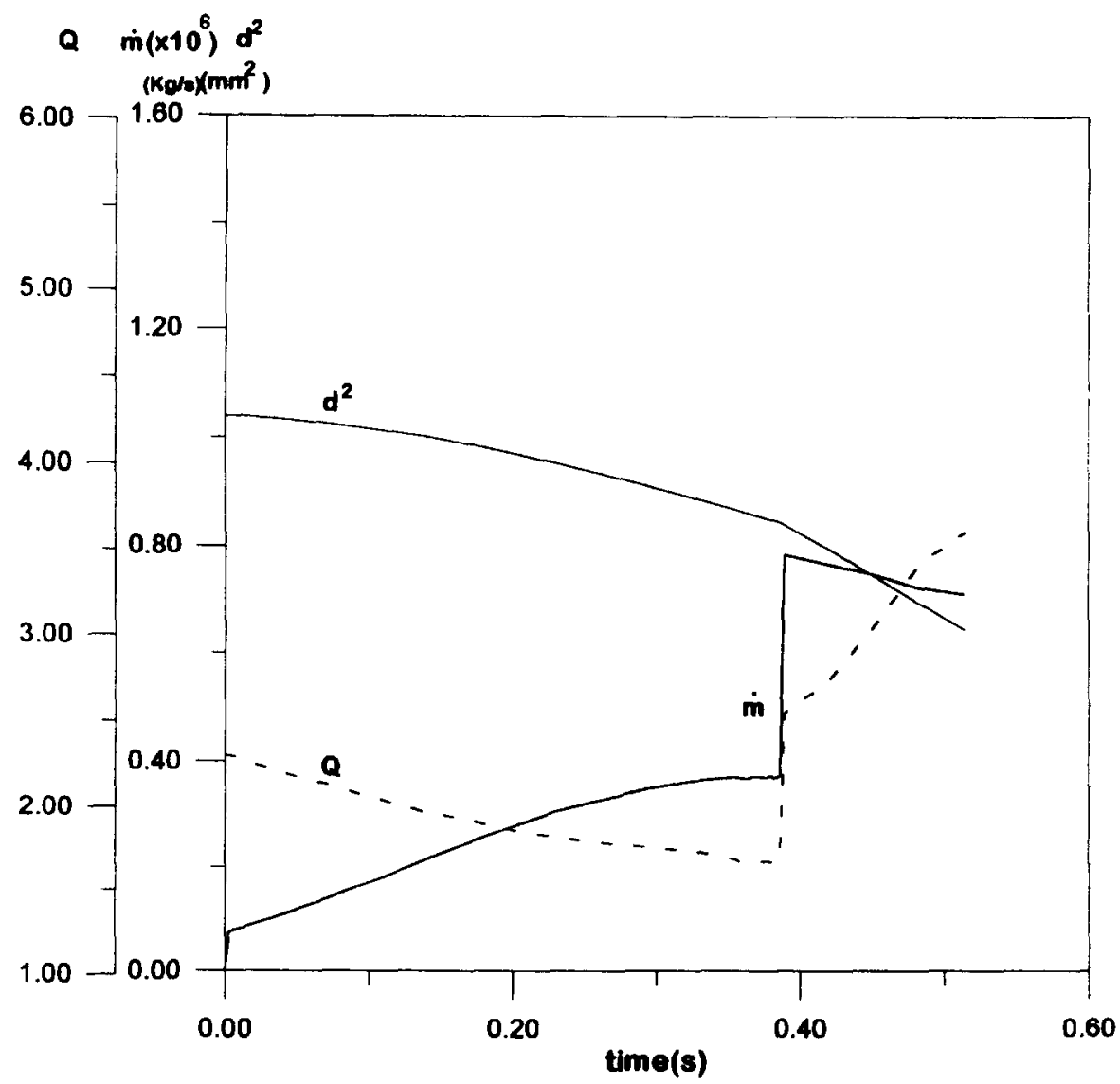

Fig. 8. The square of droplet diameter $\left(\bar{d}^{2}\right)$, the mean surface heat flux $(Q)$, and the mass evaporation $(\dot{m})$ for Case 2 . 

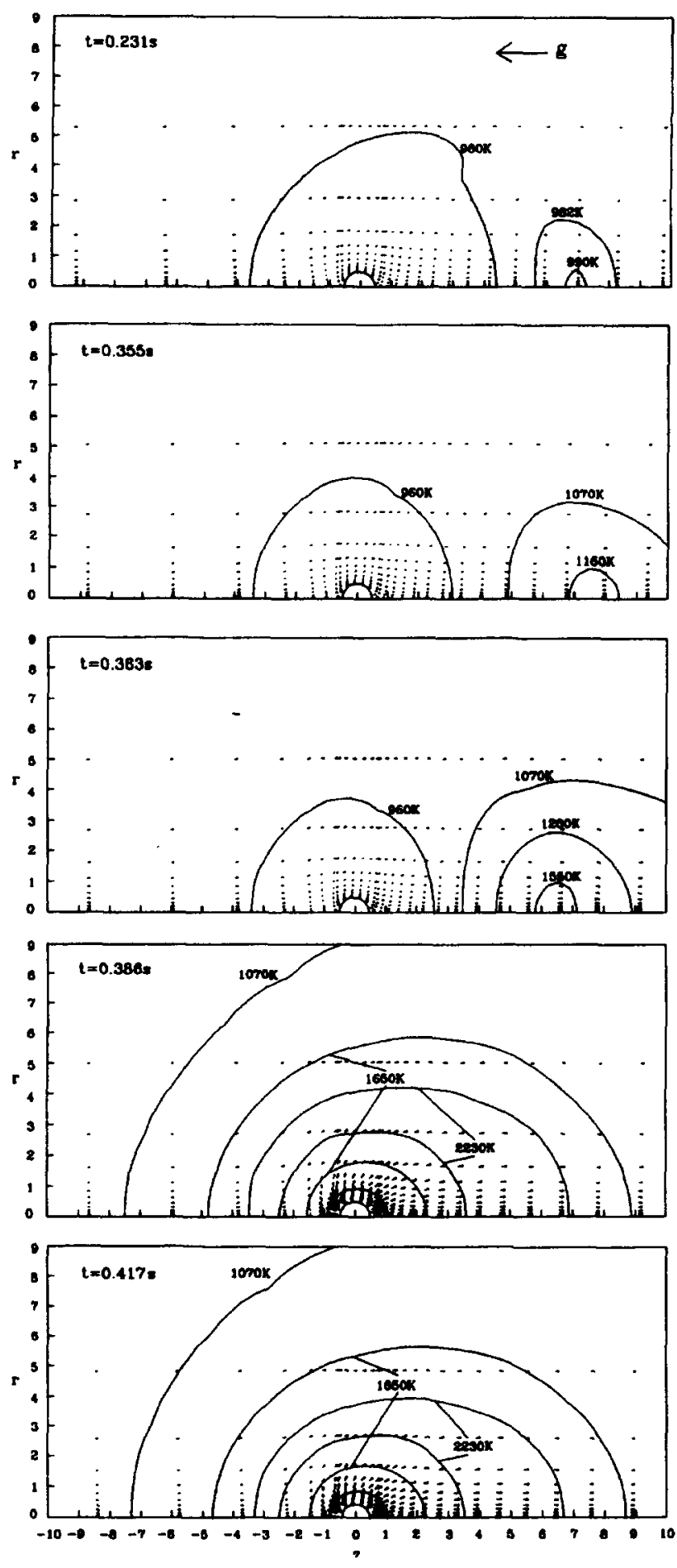

Fig. 9. Isotherm distributions for Case 2.

begins, the incoming flow is reinforced by the buoyancy force. More oxidizer is generally brought to the reaction zone to enhance the combustion. Therefore, ignition occurs earlier. The ignition delay is found to be $0.386 \mathrm{~s}$ for
Case 2, whereas in Case 1, it is $0.389 \mathrm{~s}$. Moreover, the flame in Case 2 is subjected to more stretching and is pushed closer toward the droplet. This finding suggests that the entire process is different because of the existence of 
gravity. Furthermore, its effect should be considered when analyzing the droplet ignition in a convective environment.

\section{CONCLUSIONS}

A theoretical analysis has been developed and solved numerically to study the ignition behaviors of an $n$-heptane droplet in a convective environment. Two different ambient conditions, i.e., a forced convection and a mixed convection, have been performed. The temperature of the droplet is assumed to be uniform throughout, but is a function of time. The governing system consists of axisymmetrically two-dimensional Navier-Stokes' momentum (including a body-force term), energy, species and continuity equations, and a one-step overall chemical reaction with finite-rate global kinetics. Additionally, the Clausius-Clapeyron law is applied at the liquid-vapor interface to describe the evaporating process. The Damköhler number, Reynolds number, and Grashof number, which are functions of instantaneous droplet diameter, must be updated from time to time.

The entire process can be divided into three stages: a heating-up evaporation, followed by a nearly constant droplet-temperature evaporation, and after ignition, the constant-droplettemperature burning. During the heating-up period, the droplet temperature rises to a wetbulb temperature of evaporation with slight change in droplet diameter. Followed by an evaporation process, $\bar{d}^{2}$ decreases linearly with time and the droplet temperature remains nearly constant. After ignition, a flame surrounds the droplet and a linear relation still exists between $\bar{d}^{2}$ and time. The presence of gravity markedly affects the ignition process. This occurrence suggests that the initiation of chemical reaction takes place in a location closer to the droplet, the evaporation rate after ignition is lower, and the flame stretch is greater. However, it has only a slight influence on ignition delay time. The phenomenon of fuel vapor accumulation is also identified and, after ignition, it contributes to a reduction in fuel evaporation rate.

This primary study makes several considera- tions in the final section so that the same conditions can be achieved as much as possible. Among the proposed future works would be to first take into consideration both the internal circulation and heat transfer inside the droplet. Part of this extension, the influence of internal recirculation, has recently been accomplished [24]. Next, we intend to investigate the effects by altering the ambient temperature, the incoming velocity, and the gravity level, whose directional effect may be included as well. The initial droplet diameter is also an important factor in analyzing ignition, particularly when there is a related experiment, such as in Ref. 10, which can ascertain the accuracy of the modified model. These issues will be explored in the near future.

Finally, we should address the chemical kinetics used in this work. The chemical kinetics for the fuel ( $n$-heptane), of course, is a primary concern for us because it exerts a great influence on ignition behaviors, particularly the ignition delay time. To confirm how close the present chemical kinetics are to the multistep kinetics, an effort is made to compare the corresponding computational and experimental results. Both the detailed and the reduced four-step kinetics exist for $n$-heptane ignition at a high pressure environment (40 atm), as confirmed by shock-tube experiments [25]. A subsequent work by Ciezki and Adomeit [26] using the same apparatus measured the ignition delay times of $n$-heptane-air mixture under an initial pressure of between 3.2 and 42 bar, an initial temperature of between 660 and $1350 \mathrm{~K}$, and an equivalence ratio ranging from 0.5 to 3.0. We use the data extracted from Figs. 4-6 to roughly estimate the last two references. At $t=0.386 \mathrm{~s}$, defined as the onset of reaction, the equivalence ratio of the fuel-air mixture behind the droplet approximately ranges from 2.3 to 2.6 and the averaged temperature is around $1250 \mathrm{~K}$. The ignition delay between the reaction initiation and the fully developed flame surrounding the droplet is 3 ms. It is about 100 times greater than the estimated value, as obtained from Fig. 3 of Ref. 25, using the four-step kinetic model at 40 atm environment and using the equivalence ratio and temperature of this study. If the 
pressure effect on the kinetic expression used in this study is considered, we believe that the discrepancy will be lowered to at least 1 order of magnitude. In Fig. 3 (ignition delay times) of Ref. 26, when we substitute $T=1250 \mathrm{~K}$ into the Arrhenius expression $(1000 / T)$ in the abscissa, and fit it into the measured data at a pressure of 3.2 bar, the ignition delay time is found to be $0.3 \mathrm{~ms}$, which is one-tenth of the present delay time, $3 \mathrm{~ms}$. Meanwhile, an ignition time of $0.07 \mathrm{~ms}$ is obtained by extrapolating to the computational curve of Warntz et al. at 40 bar in the same figure. The value of 0.07 $\mathrm{ms}$ is approximately one-half of the estimated time calculated in the previous study [25]. In their work, Ciezki and Adomeit [26] observed that the pressure effect causes the degree to vary in the high-temperature region. By also considering the different physical conditions between this work and the last two studies, we conclude that the one-step overall kinetics we used is not too far off from the multistep kinetics proposed by the related experiments, which more or less supports the validity of this study.

Applying one-step overall chemical kinetics similar to the current model to accurately predict the ignition phenomena is still somewhat unrealistic. On the other hand, the multidimensional computational work cannot realistically handle the complex kinetics mechanism. Therefore, applying multistep (greater than four steps) kinetics is only for one-dimensional problems, such as the flames in a stagnationpoint flow field or a shock-tube configuration. To make a compromise between the chemical and physical features, using semiglobal chemical kinetics is recommended to incorporate with the multidimensional model. In this manner, a more thorough knowledge of the ignition criterion and the related flame development can be obtained.

Financial support of this research by the $\mathrm{Na}$ tional Science Council of the R.O.C., under project \#NSC 84-2212-E-009-048, is greatly appreciated.

\section{REFERENCES}

1. Nishiwaki, N., Fifth Symposium on Combustion, Reinhold, New York, 1955, p. 148.

2. Elwakil, M. M., and Abdou, M. I., Fuel 45:177 (1966).

3. Faeth, G. M., and Olson, D. R., SAE Trans. 77:1793 (1968).

4. Sangiovanni, J. J., and Kesten, A. S., Combust. Sci. Technol. 16:59 (1977).

5. Saitoh, T., and Nagano, O., Combust. Sci. Technol. 22:227 (1980).

6. Rah, S. C., Sarofim, A. F., and Beer, J. M., Combust. Sci. Technol. 49:169 (1986).

7. Law, C. K., Combust. Flame 24:89 (1975).

8. Mawid, M., and Aggarwal, S. K., Combust. Sci. Technol. 65:137 (1989).

9. Takei, M., Tsukamoto, T., and Niioka, T., Combust. Flame 93:149 (1993).

10. Wong, S. C., and Ho, J. T., 4th National Conf. Combust. Sci. Technol., Taiwan, 1994, p. 126.

11. Rangel, R. H., and Fernandez-Pello, A. C., Prog. Aero. \& Astr. 105:239 (1986).

12. Dash, S. K., and Som, S. K., I. Energy Resources Technol. 113:165 (1991).

13. Yang, J. T., and Tsai, G. T., Combust. Sci. Technol. 96:1 (1994).

14. Westbrook, C. K., and Dryer, F. L., Combust. Sci. Technol. 27:31 (1981).

15. Reid, R. C., Prausnitz, J. M., and Poling, B. E., The Properties of Gases \& Liquids. McGraw-Hill, Singapore, 1988.

16. Thomas, P. D., and Middecoff, J. H., AIAA J. 18:652 (1980).

17. Van Doormaal, J. P., and Raithby, G. D., Numerical Heat Transfer 7:147 (1984).

18. Huang, L. W., and Chen, C. H., Wärme-undStoffübertragung 29:415 (1994).

19. Huang, L. W., and Chen, C. H., Numerical Heat Transfer, Part A, 27:53 (1995).

20. Huang, L. W., and Chen, C. H., accepted by Ẅarmeund-Stoffiubertragung (1995).

21. Kanury, A. M., Introduction to Combustion Phenomena, Gordon and Breach, New York, 1975.

22. Rosner, D. R., in Liquid Propellant Rocket Combustion Instability (D. T. Harrje and F. H. Reardon, Eds.), NASA SP-194, Washington, 1972.

23. Law, C. K., Combust. Sci. Technol. 42:325 (1985).

24. Huang, L. W., and Chen, C. H., submitted to International Heat Mass Transfer J. (1995).

25. Muller, U. C., Peters, N., and Linan, A., Twenty-Fourth Symposium in Combustion, The Combustion Institute, Pittsburgh, 1992, p. 777.

26. Ciezki, H. K., and Adomeit, G., Combust. Flame, 93:421-433 (1993).

Received 30 June 1995; revised 26 April 1996 